\title{
Generalized Approach for DCPWM Based Dual Inverter Fed OEWIM-DTC Drive.
}

\author{
M Nalini Devi, R Srinu Naik
}

\begin{abstract}
A generalized procedure of decoupled pulse width modulation (DCPWM) based on Method called Direct Torque Control (DTC) for Open Ended Winding Induction motor drive (OEWIM) is anticipated in this paper. This drive topology uses two isolated dc sources with equal magnitudes, feeding two standard two level three-phase inverters. To overcome the complexity in classical space vector pulse width modulation (SVPWM) algorithm, a simple generalized approach is presented in this research by using the phase voltages. With this procedure, various $P W M$ algorithms can be generated by varying a constant value. The dual inverters are operating independently with half of the switching frequency. To show the usefulness of proposed PWM fed DTC drive, simulation results analysis has been carried out by using MATLAB and results obtained.
\end{abstract}

Key Words: DTC, Generalized PWM, SVPWM, OEWIM.

\section{INTRODUCTION}

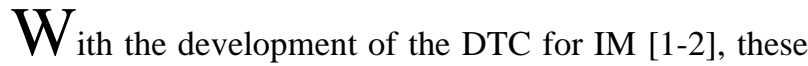
are employed in high performance industrial applications. This method is simple for implementation and gives a fast dynamic response. However, the Direct Torque Control suffers from drawbacks such as variable switching frequency and more steady state ripple. Also, the DTC with two level inverter cannot handle high power applications. Hence, to meet high power applications, a variety of multilevel inverter (MLI) topologies such as diode clamped, capacitor clamped, cascaded, etc were projected to the DTC fed drives. However, these topologies give neutral point oscillations or require much number of sources or capacitors and unbalancing problems. In order to overcome above said problems, later a new topology called open-end winding topology proposed in [3-6].

As the name indicates, in this configuration both ends of three phase windings of induction motor will fed by two individual inverters on both sides. With this configuration, the drawbacks of MLI topologies can be rectified. Moreover, this topology gives the output voltage similar to that of MLI topology and hence, these topologies will be appropriate for high power applications. Moreover, these topologies will reduce the harmonic distortion when compared to two-level

Manuscript received on July 12, 2021.

Revised Manuscript received on July 18, 2021.

Manuscript published on 30 July , 2021.

* Correspondence Author

M Nalini Devi*, Assistant Professor, Department of Electrical Engineering, Mahatma Gandhi Institute of Technology (MGIT), Hyderabad (Telangana), India. E-mail: nalinimaanasa@gmail.com

Dr. R Srinu Naik, Assistant Professor, Department of Electrical Engineering, AU College of Engineering, Vishakhapatnam (Andhra Pradesh), India. Email: naiknaiknaik@gmail.com

(c) The Authors. Published by Blue Eyes Intelligence Engineering and Sciences Publication (BEIESP). This is an open access article under the CC BY-NC-ND license (http://creativecommons.org/licenses/by-nc-nd/4.0/) inverter fed drives. As the only half of the total summed power supply is given to the both inverters, the switching s harmonics and hence switching losses are reduced. Because of the above said advantages, this topology is becoming popular in many industrial and commercial applications and ship propulsion applications [6].

In order to generate variable voltage and variable frequency from inverter it is necessary to use PWM methods. Among the different Pulse width modulation techniques, space vector PWM [7] is popular due to its numerous advantages such as less harmonic distortion, etc,. However, this technique requires complex calculations to generate the switching times. Hence, to reduce the complexity different approaches were projected in [8-11]. These approaches use either instantaneous voltages or imaginary switching time concept to derive the switching times.

In the instantaneous voltage concept, sampled reference phase voltage is extended to MLI topology in [12] for any no. of levels. In this approach, the modulating signal will be generated based instantaneous voltage and then suitable number of triangles will be selected based on the n-number of MLI topology. Similarly, the imaginary switching time is extensive to OEWIM topology in [13-15]. The approaches projected in [12-15] dealt with SVPWM only. But, the methods proposed in [8-11] proved that at elevated modulation indices discontinuous PWM (DPWM) methods will give superior wave form quality with reduced switching losses.

Hence, the proposed paper presents a simplified and generalized approach based decoupled PWM (DCPWM) transition to the OEWIM drive, which uses the concept of instantaneous voltages only. Also,, in this methodology by tuning constants, different PWM methods are derived. To show the usefulness of the projected approach, numerical simulation results were presented.

\section{OEWIM CONFIGURATION}

The topology of OEWIM drive is as represented in Fig.1, in which dual inverters will be fed with an equal isolated DC power supplies $((1 / 2) \mathrm{Vdc})$ as shown in Fig.1. Here the $V_{\mathrm{dc}}$ is the total applied input DC voltage, which is equivalent to a single two-level inverter.

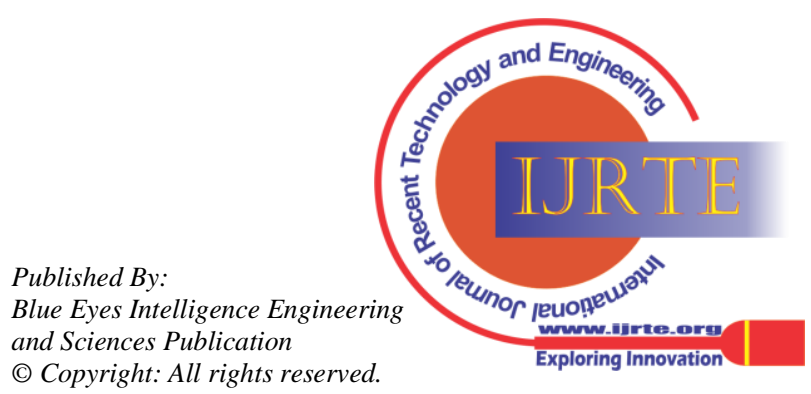


Generalized Approach for DCPWM Based Dual Inverter Fed OEWIM-DTC Drive.

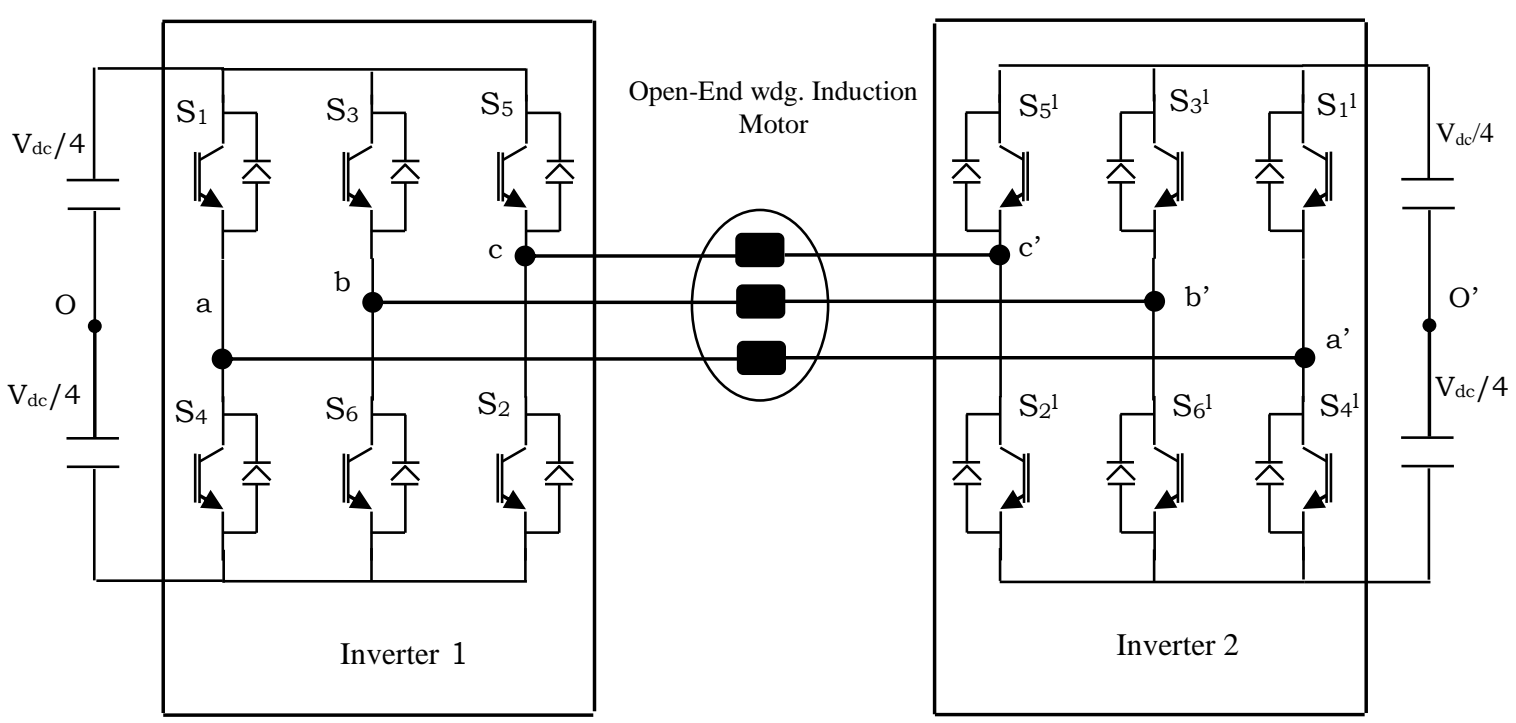

Fig. 1 Configuration of OEWIM drive

The pole voltages of inverter-1 and inverter 2 are represented by Vao, Vbo and Vco and Va'o, Vb'o and Vc'o respectively. The voltage vectors of SVPWM of each two single inverter are shown in Fig.2. the numbers 1 to 6 refer the active states of inverter- 1 and numbers 1 ' to 6 ' refer the active states of inverter- 2 . The centers of inverter- 1 and inverter- 2 represent the zero voltage vectors.

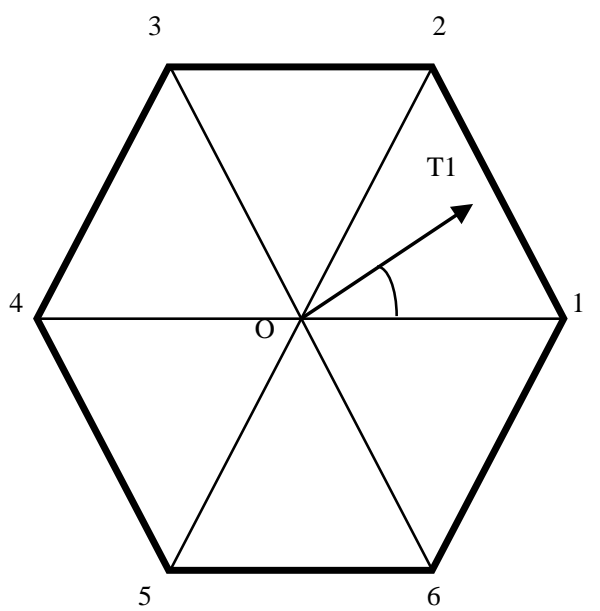

Inverter-1

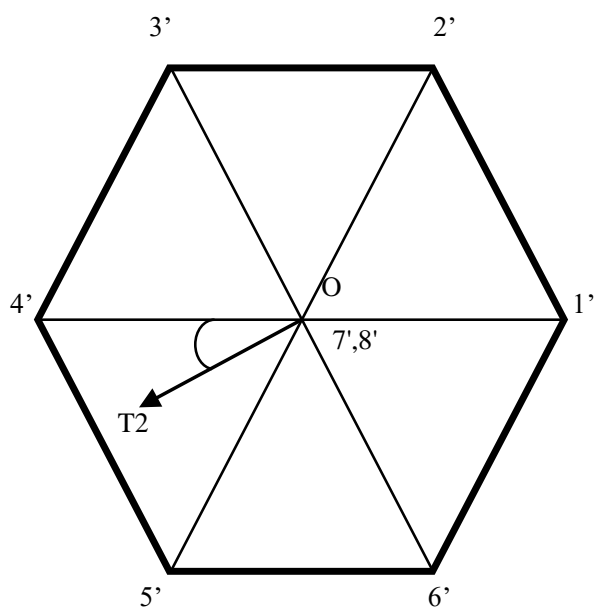

Inverter-2

Fig: 2 Switching of each individual inverters

The superimpose of two two-level inverters space vector diagrams is shown in Fig.3, which is equivalent to a space vector diagram of three-level inverter. As represented earlier, the numbers 1 to 8 and 1' to 8' indicate the active and zero states of two inverters. The sum of balanced sinusoidal three phase voltages is zero and usually this sum is known as zero sequence voltage. But, as the inverter generates pulsed type of instantaneous phase voltages, sum of the motor phase voltages will not be zero, which causes zero sequence voltage (ZSV). This ZSV would cause a strong zero sequence current, which is ruinous to the semi- conductor switching devices and the motor. However, this technology uses isolated DC sources, this topology will not provide a path to the zero sequence current. Though, the zero sequence current is zero the ZSV will present in the instantaneous values of the difference in pole voltages (Vaa', Vbb' and Vcc') across the points $\mathrm{O}$ and $\mathrm{O}^{\prime}$. The ZSV is represented as in (1) 


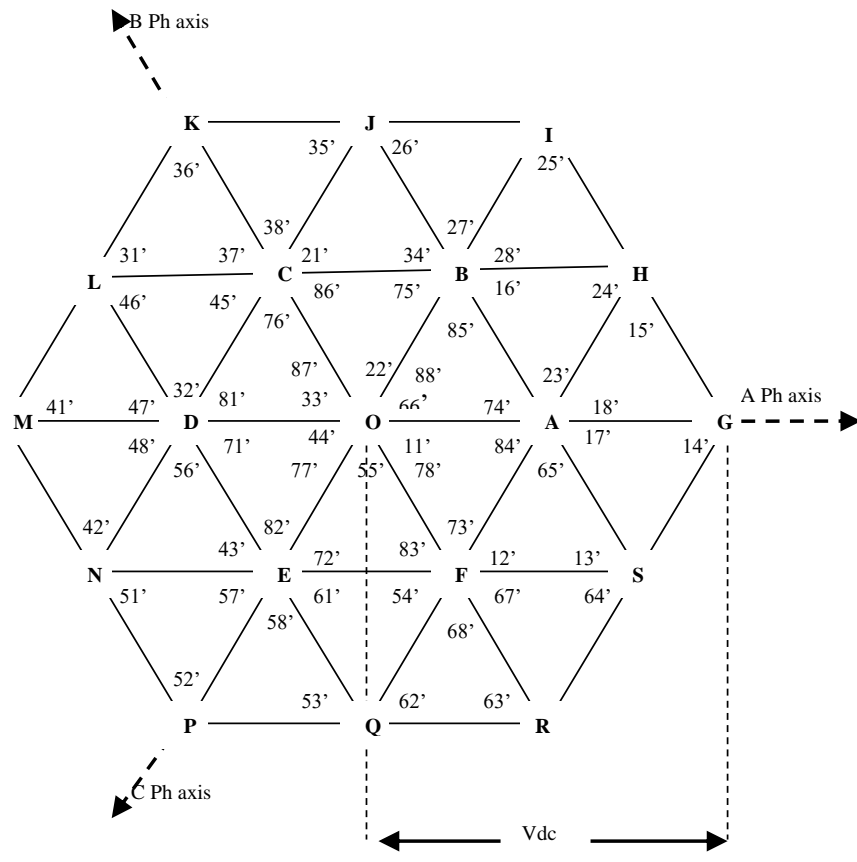

Fig: 3 Equivalent three level space vector pulse width modulation for inverters control

$$
\mathrm{Vzs}=\frac{\mathrm{Vaa}^{\prime}+\mathrm{Vbb}+\mathrm{Vcc}}{3}
$$

\section{A. Proposed Generalized Approach Based DCPWM Algorithm:}

In Fig. 4(b), the vector notation of OT denotes the required reference voltage vector $\left(\left|\mathrm{V}_{\text {ref }}\right| \angle \alpha\right)$, which is to be synthesized from the two inverters. This vector is results into two opposite components of $\mathrm{OT}_{1}\left(\left|\mathrm{~V}_{\text {ref }} / 2\right| \angle \alpha\right)$ and $\mathrm{O}^{\prime} \mathrm{T}_{2}$ is $\left(\left|\mathrm{V}_{\text {ref }} / 2\right| \angle \beta\right)$. The vectors $\mathrm{OT}_{1}$ and $\mathrm{O}^{\prime} \mathrm{T}_{2}$ will be constructed by inverters 1 and 2 .

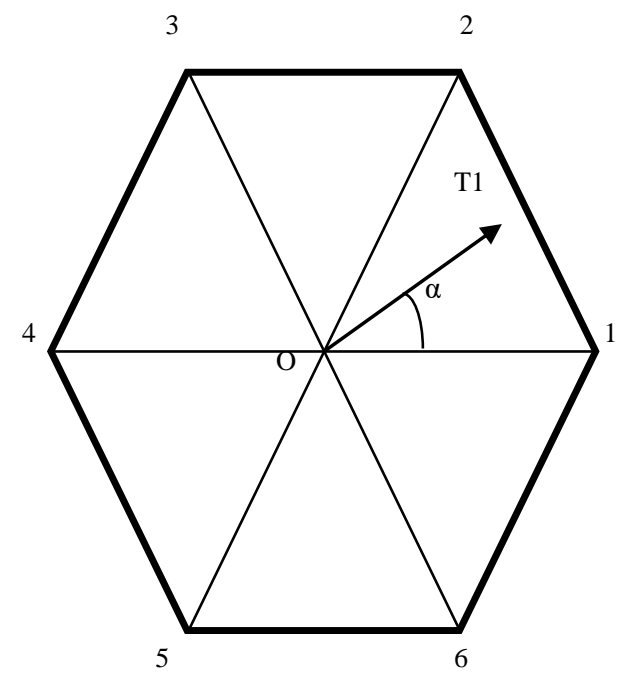

Inverter-1

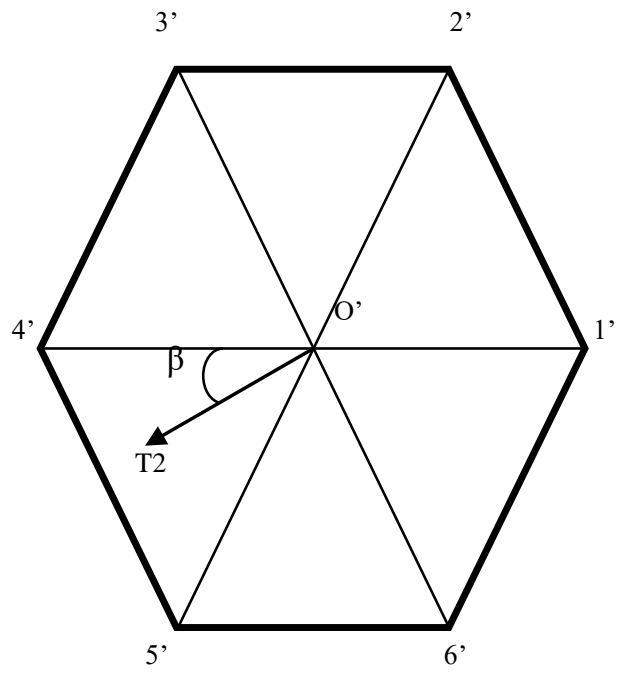

Inverter-2

Fig.4 (a): Space vectors of inverter-1 and 2

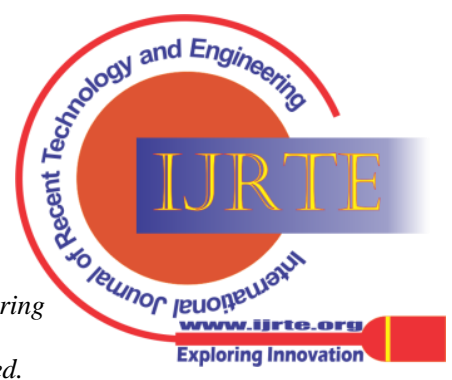




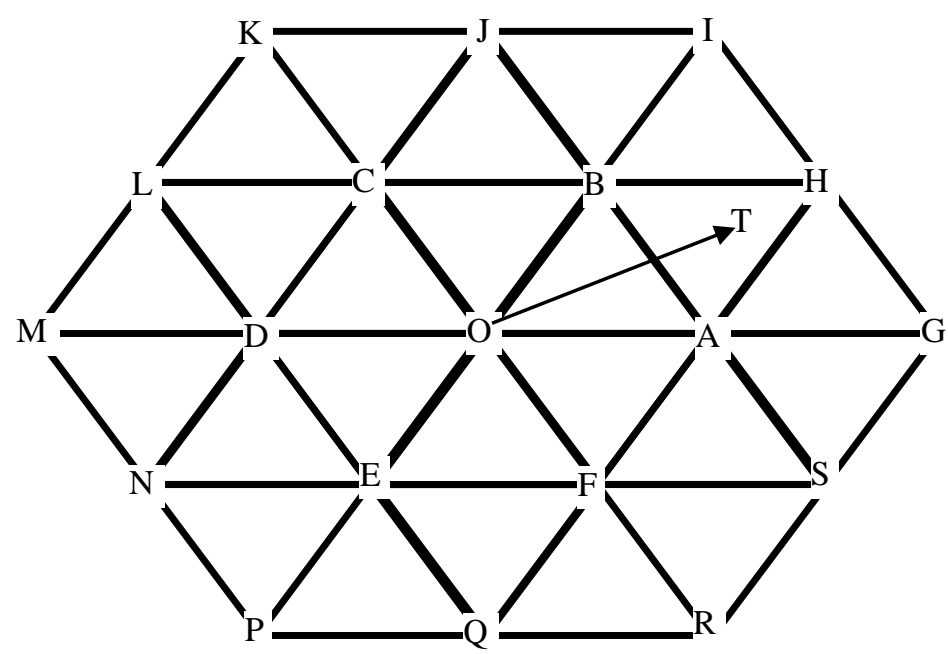

Fig. 4 (b) Equivalent 3-level space vector plane

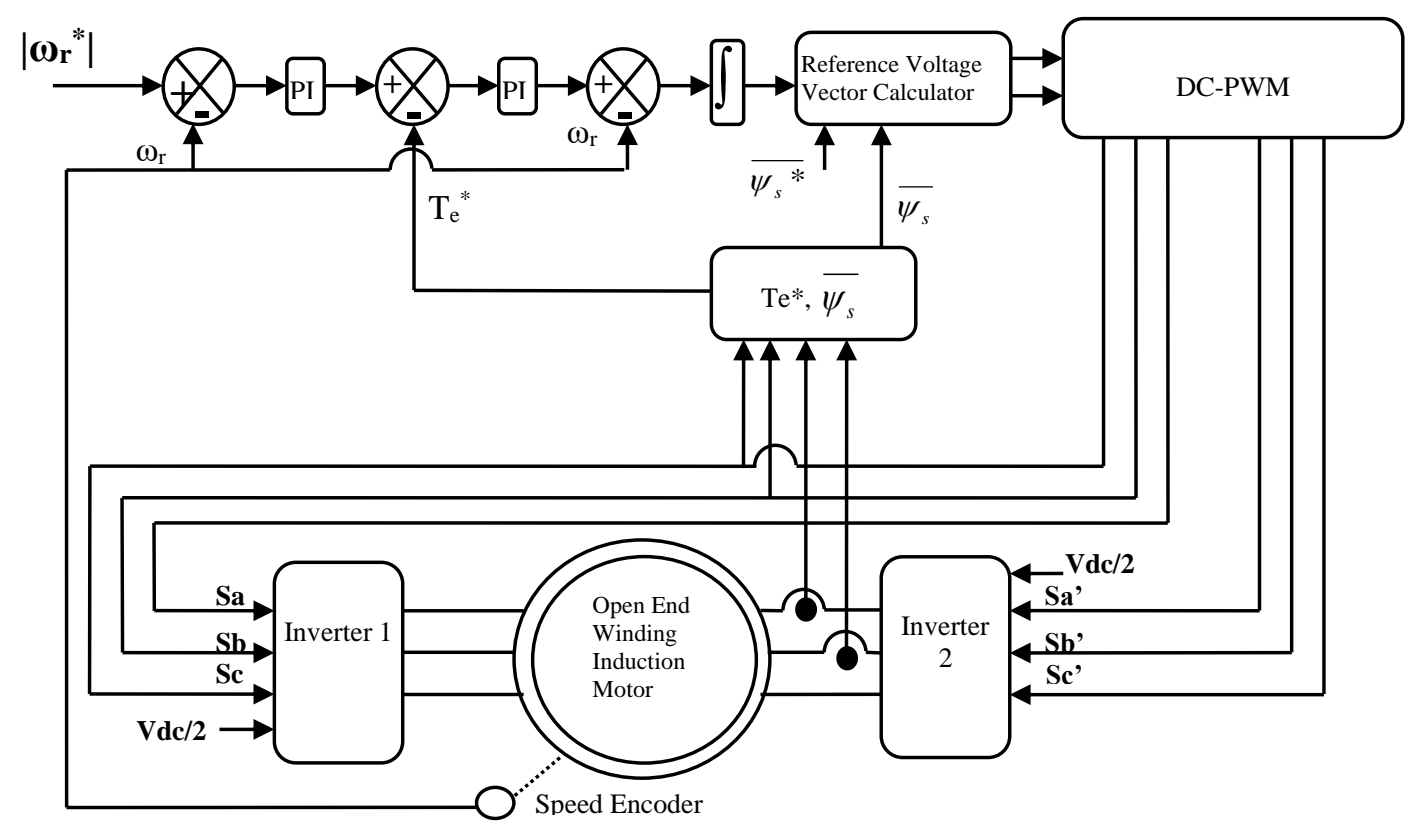

Fig.5 Block diagram of proposed DC-SVPWM based DTC

To attain the 3 level output first inverter output is superposed on the second inverter output at each vector position, which gives a space vector plane that equivalent to a three level plane. In the decoupled PWM method, both inverters will operate with a phase shift of $180^{\circ}$ between the modulating signals of both inverters. In order to minimize the complexity in the classical SVPWM approach, a simplified approach [10-11] is proposed for OEWIM drive. Consider the set of three-phase voltages as $v_{n}$, where $n=a, b$ and c . Then, the referencing signals for sinusoidal PWM (SPWM) are derived as given in (2).

$$
v_{n}^{*}=p+\frac{v_{n}}{V_{d c}}
$$

Here, $V_{\mathrm{dc}}$ is dc-link voltage. For SPWM method, the value of $p$ is taken as0.5. By adding a ZSV $\left(v_{Z}\right)$ to the $v_{n}$, necessary modulating signals for SVPWM and DPWM techniques can be resulting [8-11] as given in (3).

$$
v_{n}^{*}=p+\frac{v_{n}+v_{Z}}{V_{d c}}
$$

The ZSV can be expressed as given in (4).

$$
v_{Z}=k\left[\min \left(v_{n}\right)-\max \left(v_{n}\right)\right]-\min \left(v_{n}\right)
$$

Except for SPWM technique, in all other techniques (SVPWM and DPWM) the value of $p$ is taken as $p=k$. By alternating the value of $\mathrm{k}$ between 0 and 1 , different PWM techniques can be derived. To derive the modulating signals of SVPWM technique, the value of $k$ is taken as 0.5.

The modulating signals of DPWMMAX and DPWMMIN techniques can be derived by taking the $k$ value as 1 and 0 respectively. To derive the modulating signals for other DPWM techniques, the $k$ is defined as in (5).

$$
k=0.5(1+\operatorname{sgn}(\cos (3 \omega t+\delta))
$$

where $\operatorname{sgn}(\mathrm{x})$ is $-1,0$ and 1 when $\mathrm{x}$ is negative, zero, and positive, respectively.

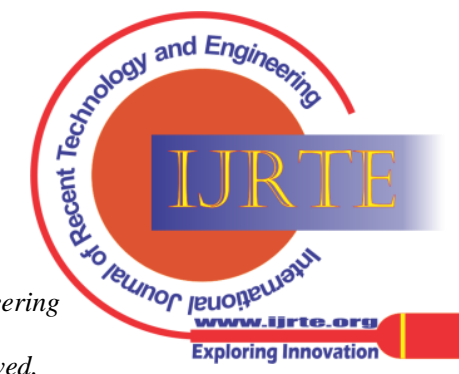


By changing the modulation angle $(\delta)$ in equation (4) other DPWM techniques can be generated. The DPWM0, 1, 2 and 3 can be resulted for $\delta=\pi / 6,0,-\pi / 6$ and $-\pi / 3$ correspondingly. the block diagram of proposed PWM based DTC fed OEWIM drive is shown in Fig.5. In this method, dand qaxes reference values will be compared with the actual values.

Then by dividing the error values of flux signals with switching time period, the corresponding $\mathrm{d}$ - and q-axes phase voltage will be generated [15]. Then, these 18 two-phase voltages will be converted into three-phase voltages. The modulating signals can be derived as per previous section and by comparing which the pulses can be generated. The pulse generated is fed to the inverters which are fed with the induction motor on either ends which results in a three level output voltage.

\section{RESULTS AND DISCUSSIONS}

To analize the performance of proposed generalized approach based decoupled PWM technique based DTC, Mathematical analysis was conceded using MATLAB simulation and output results are presented. The specifications of the induction motor used for simulation study are as follows:

A 3-phase, 4 pole, $4 \mathrm{~kW}, 1440 \mathrm{rpm}$ induction motor with $\mathrm{R}_{\mathrm{s}}$ $=1.57 \Omega, \mathrm{R}_{\mathrm{r}}=1.21 \Omega, \mathrm{L}_{\mathrm{s}}=\mathrm{L}_{\mathrm{r}}=0.17 \mathrm{H}, \mathrm{L}_{\mathrm{m}}=0.165 \mathrm{H}$ and $\mathrm{J}=$ $0.089 \mathrm{Kg} . \mathrm{m}^{2}$. The simulation of OEWIM-DTC Drive control of induction motor is done by using MATLAB-IMULINK. The results for different cases are given below.

For the analysis, the switching frequency is considered as $3 \mathrm{kHz}$. Hence, to continue constant switching frequency, the switching frequency is taken as $3 \mathrm{kHz}$ for SVPWM and $4.5 \mathrm{kHz}$ for all remaining DPWM methods [8-11]. The steady state waveforms for different PWM techniques based DTC are represented in from Fig. 6 to Fig. 11. From the simulation results it can be observed that the DPWM1 results in superior waveform quality and gives reduced harmonic distortion.

A. Case-1: Open Ended Winding IM using DTC,

Reference speed $=100 \mathrm{rad} / \mathrm{sec}$

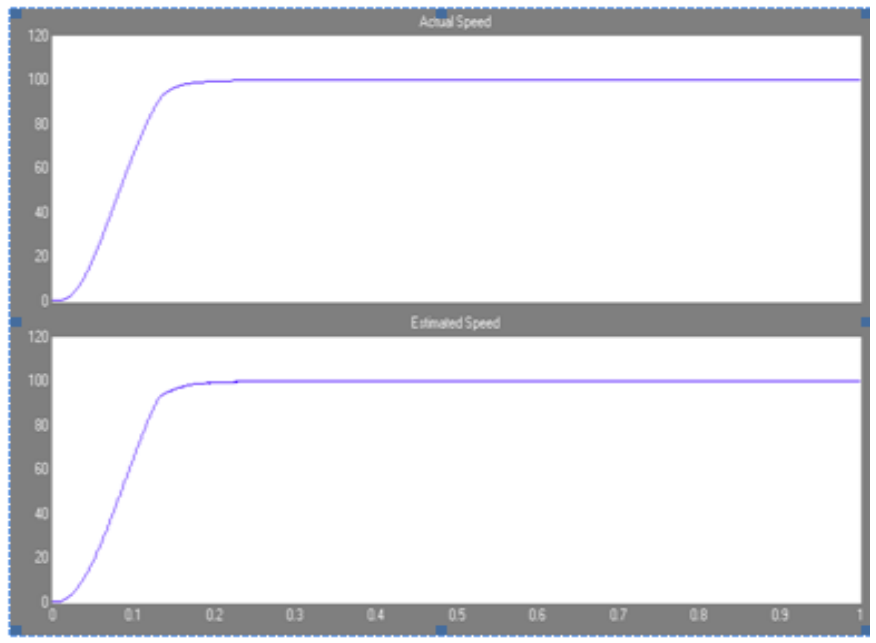

Fig 6 Actual Speed and Estimated speed using DTC in $\mathrm{rad} / \mathrm{sec}$

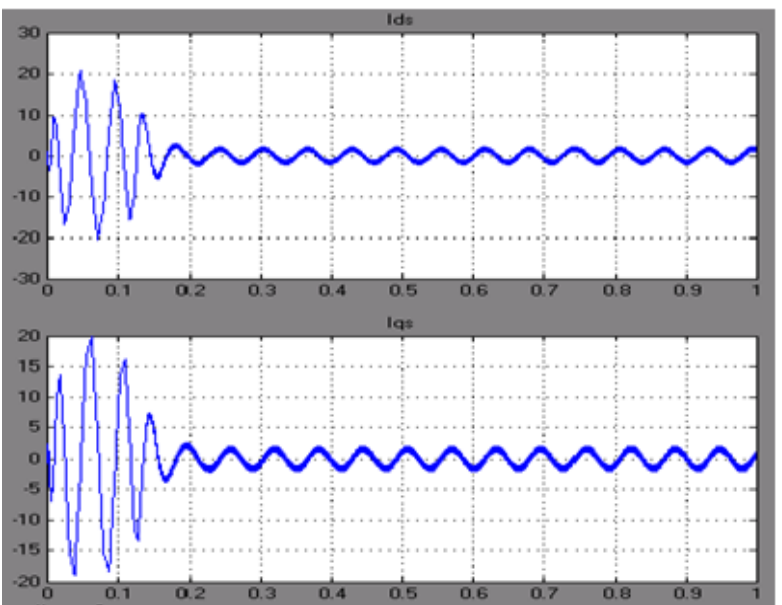

Fig.7(a) Direct and Quadrature axes currents (Ids \& Iqs)

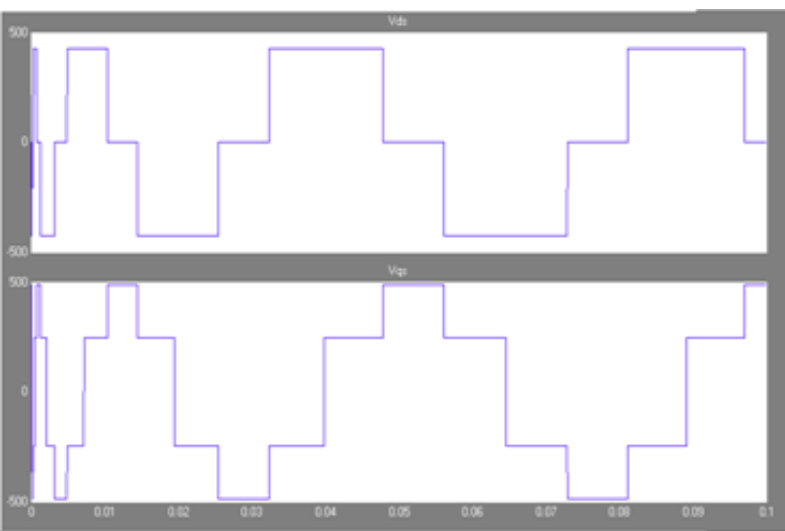

Fig 7(b) Direct and Quadrature axes voltages (Vds \& Vqs)

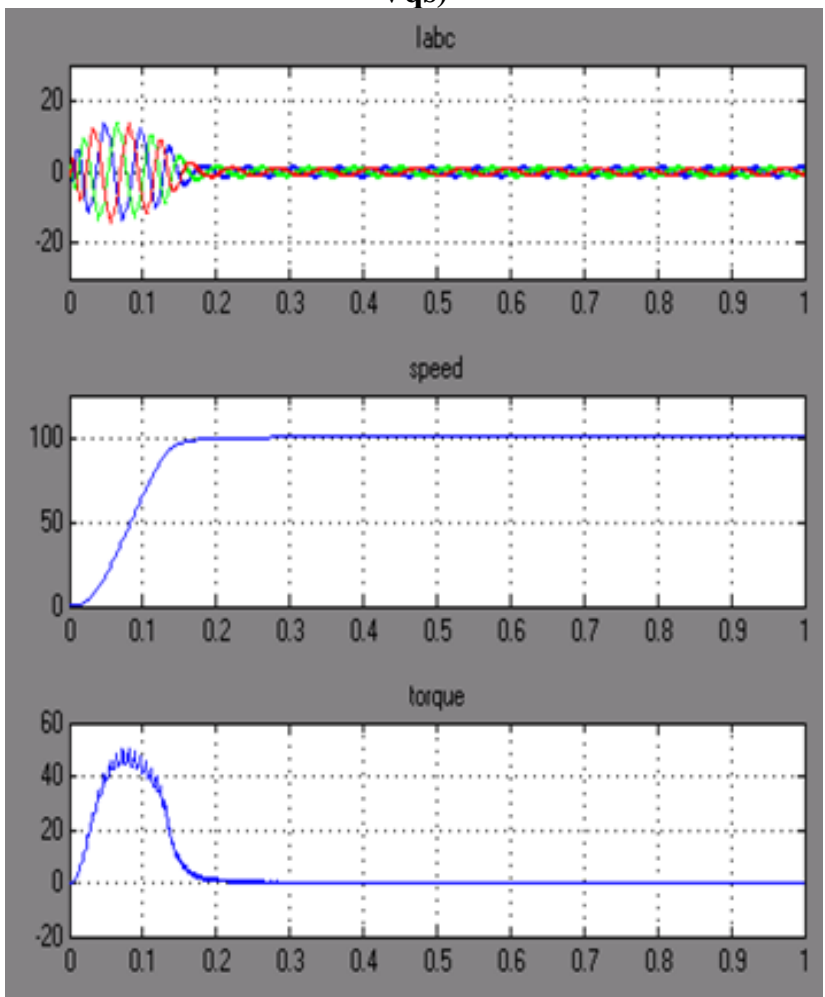

Fig.8(a) Line currents in Amps (b) Speed in rad/sec (c) Torque in N-m on no load

Published By:

Blue Eyes Intelligence Engineering and Sciences Publication

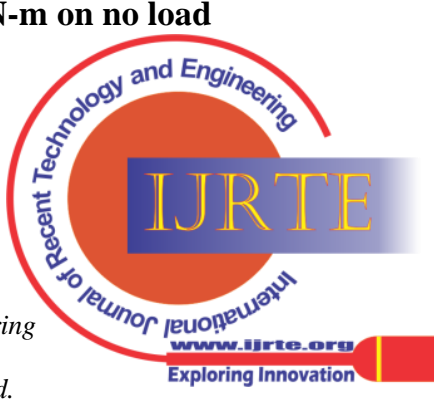




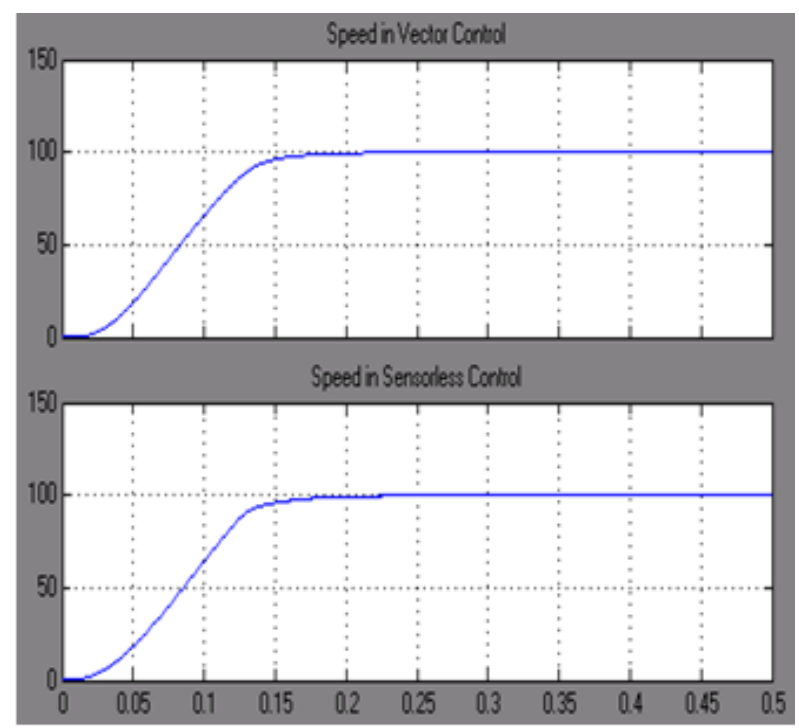

Fig. 9 Speed in Vector Control and DTC Control

Fig.6 Shows that the actual speed of open ended induction motor and estimated speed using DTC are same. Fig. 7(a) Show direct and quadrature axes currents (Ids \& Iqs). From the graph it is observed that both currents are displaced by 900. Hence the coupling effect can be eliminated. Fig.8 shows the no load line currents, speed and torque wave forms. It can be seen that at starting the values of currents and torque will be high. The motor reaches to its final steady state position within 0.2 sec. Hence it has fast dynamic response.Fig.9 shows the speeds obtained in the Vector Control and in DTC Control. From this it is observed that the speed obtained in the DTC Control is same as Vector Control without any speed sensors.

Case-2: Step Change in Load

Reference speed $=100 \mathrm{rad} / \mathrm{sec}$, Load torque of $15 \mathrm{~N}-\mathrm{m}$ is applied at $\mathrm{t}=0.25 \mathrm{sec}$.

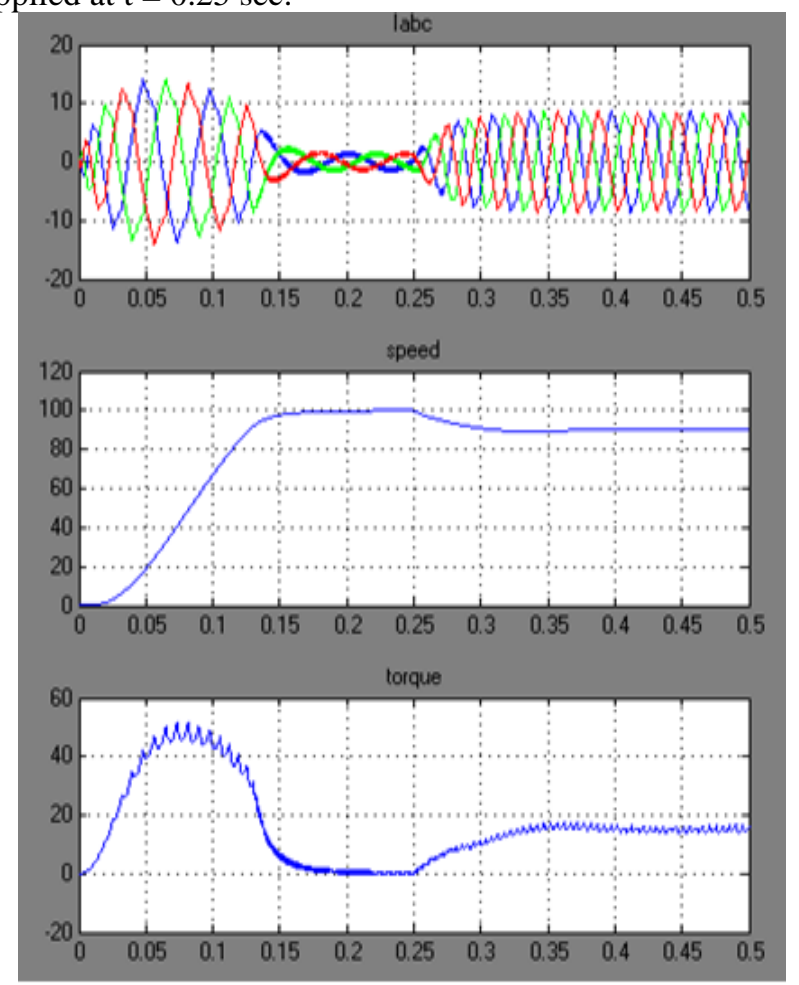

Fig.10 (a) Line currents in Amps (b) Speed in rad/sec (c) Torque in N-m on step change in load
Fig.10 shows the line currents, speed and torque wave forms under load condition. First the motor is started under no load and at $\mathrm{t}=0.25 \mathrm{sec}$ a load of $15 \mathrm{~N}$-m is applied. It can see that at $0.25 \mathrm{sec}$, the values of currents \& torque will increase to meet the load demand and at the same time speed of motor is slightly falls.

Case-3: Speed Reversal Command Reference speed $=100 \mathrm{rad} / \mathrm{sec}$; speed reversal command is applied at $\mathrm{t}=0.5 \mathrm{sec}$.

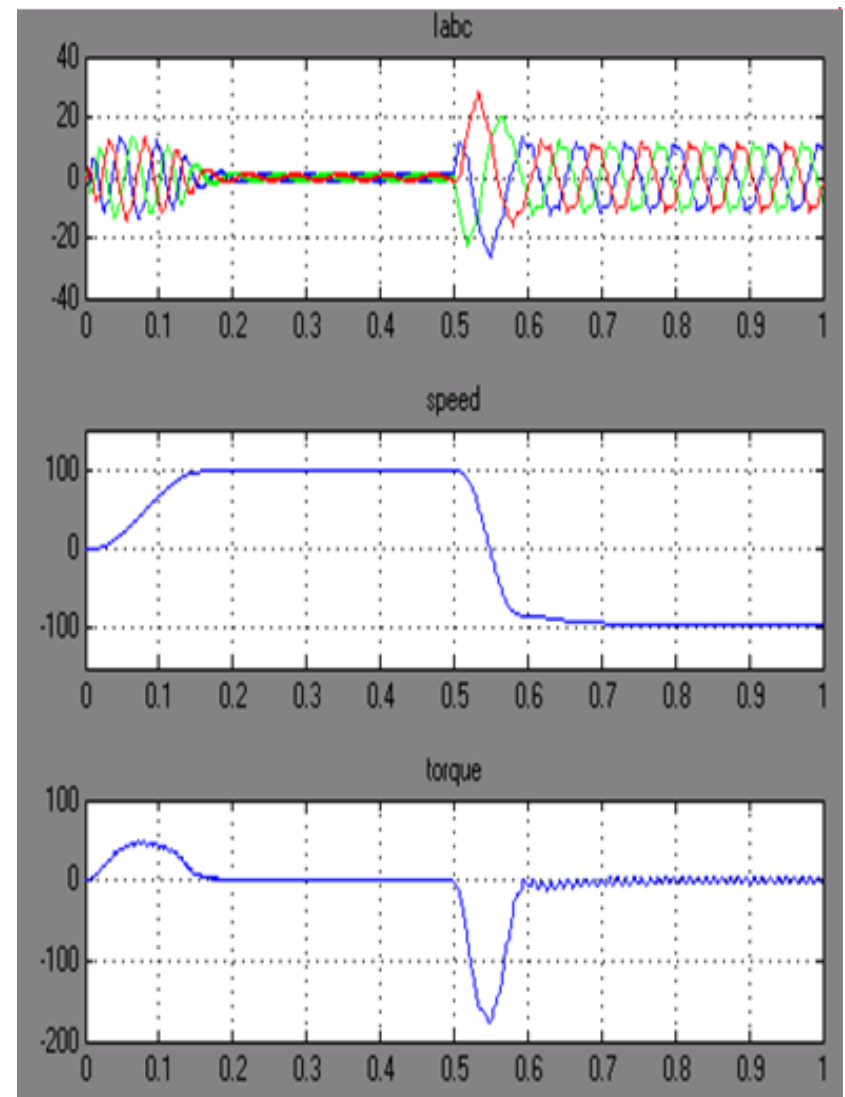

Fig.11 (a) Line currents in Amps (b) Speed in rad/sec (c) Torque in $\mathrm{N}$-m on no load, speed reversal

The motor is started under no load condition and speed reversal command is applied at $\mathrm{t}=0.5 \mathrm{sec}$. At $0.5 \mathrm{sec}$ the motor speed decays from $100 \mathrm{rad} / \mathrm{sec}$ and within $0.1 \mathrm{sec}$ it reached its final steady state in the opposite direction. At 0.5 sec torque will increase negatively and reaches to steady state position corresponds to steady state speed value.

\section{CONCLUSION}

A simplified generalized approach is proposed for decoupled PWM based OEWIM drive. The proposed approach can results into wide range of PWM algorithms in a simple manner. From the results, it can be represented that the DPWM1 results in good waveform quality and reduced harmonic distortion. Also, from the results it can shown that the DPWM methods are clamped to either positive sequence or negative sequence DC bus over a $1 / 3$ of the fundamental cycle. Hence, these DPWM techniques reduce the switching losses by $33.33 \%$.

Published By:

Blue Eyes Intelligence Engineering and Sciences Publication 


\section{REFERENCES}

1. Takahashi, T. Noguchi, "A new quick response and high-efficiency control strategy of induction motor", IEEE Trans. On IA, Vol.22, $\mathrm{N}^{\circ} .5$, Sept/Oct 1986, PP.820-827.

2. I Takahashi and Youchi Ohmari, "High -Performance Direct Torque Control of an Induction Motor,'. IEEE Tran. Industry Applications, Vol. IA-25, No.2, pp 257-264, 1989.

3. H Stemmler and P. Guggenbach, 'Configurations of High -power Voltage Source Inverter Drives,” Proc. EPE‘93, Vol., pp 7-14, 1993.

4. T kawabata, "New Open-Winding Configurations For High-Power Inverters,” Proc. ISIE‘97. Va1.2, pp 457 462, 1997.

5. KA Corzine, SD Sudhoff, CAWhitcamb, "Performance Characteristics of a Cascaded Two-Level Converter," IEEE Trans. on Energy Conversion, Vo1.14, N0.3, pp 433 -439, Sept. 1999.

6. Brain A Welchka and James M Nagashima, "A comparative Evaluation of Motor Drive Topologies for Low-Voltage, High- Power EVIHEV Propulsion Systems," IEEE International

7. Heinz Willi Vander Broeck, Hnas-Christoph Skudelny and Georg Viktor Stanke, "Analysis and realization of a pulsewidth modulator based on voltage space vectors" IEEE Trans. Ind. Applicat., vol. 24, no. 1, January/February 1988, pp. 142-150.

8. Ahmet M. Hava, Russel J. Kerkman and Thomas A. Lipo, "Simple analytical and graphical methods for carrier-based PWM-VSI drives" IEEE Trans. Power Electron., vol. 14, no. 1, Jan 1999, pp. 49-61

9. Dae-Woong Chung, Joohn-Sheok Kim and Seung-Ki Sul, "Unified voltage modulation technique for real-time three-phase power conversion" IEEE Trans. Ind. Applicat., vol. 34, no. 2, March/April 1998, pp. 374-380.

10. Antonio Cataliotti, Fabio Genduso, Angelo Raciti, and Giuseppe Ricco Galluzzo "Generalized PWM-VSI Control Algorithm Based on a Universal Duty-Cycle Expression: Theoretical Analysis, Simulation Results, and Experimental Validations" IEEE transactions on Ind. Electron., vol. 54, NO. 3, June 2007, pp 1569-1580.

11. Edison Roberto C. Da Silva, Euzeli CiprianoDos Santos, Jr., and Cursino Bradao Jacobina, "Pulsewidth modulation strategies" IEEE Ind. Electron., Magazine, no.2, pp.37-45, June, 2011.

12. R.S. Kanchan, M.R. Baiju, K.K. Mohapatra, P.P. Ouseph and K. Gopakumar, "Space vector PWM signal generation for multilevel inverters using only the sampled amplitudes of reference phase voltages" IEE Proc.-Electr. Power Appl., vol. 152, No. 2, pp. 297-309, March, 2005.

13. V.T. Somasekhar, K. Gopakumar, M.R. Bajju, K.K. Mohapatra and L. Umanand, "A Multilevel Inverter System for an Open End Winding Induction Motor with Open-End Winding," IEEE Transactions on Industrial Electronics, Vol. 52, No. 3, June 2005, pp. 824-836.

14. S. Srinivas, V.T. Somasekhar, "Space-vector-based PWM switching strategies for a three-level dual-inverter-fed open-end winding induction motor drive and their comparative evaluation", IET Electr. Power Appl., Vol. 2, No. 1, January 2008, pp. 19-31

15. Satheesh.G, Bramhananda Reddy.T, Sai Babu. CH "DTC of Open End Winding Induction Motor fed by two space-vector-modulated inverters" in Proc. IEEE INDICON, 2011.

\section{AUTHOR PROFILE}

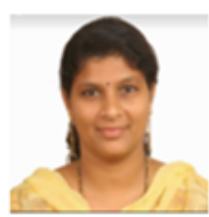

Mrs. M Nalini Devi, Obtained her B.Tech from JNTU Kakinada in 2001 and MTech from Jawaharlal Nehru Technology University Hyderabad in 2004. Now she is continuing her Ph.d (Department of Electrical Engineering) in AU college of Engineering, Vishakhapatnam. She is presently working as assistant professor in MGIT, Hyderabad.

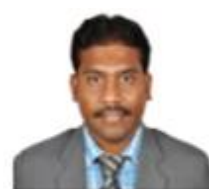

Dr. R Srinu Naik, Working as Assistant Professor in Department of Electrical Engineering AU college Engineering, Vishakhapatnam, Andhra India. He completed his B.Tech degree in 2003 and M.tech degree with specialization in Electrical Power Systems \& Automation in 2003 \& Ph.d in 2015 from.AU college of Engineering. He has 15 years of teaching experience and area of Interest included Single/Multi objective optimal operation solution on power system of Pradesh, severity and Real time energy management.

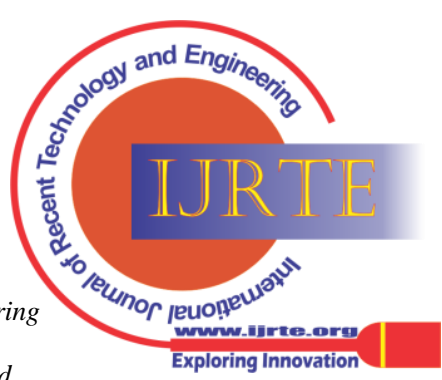

